\title{
Merkel Cell Carcinoma: Case Report and Literature Review
}

\section{Carcinoma de células de Merkel: Reporte de caso y Revisión de literatura}

\author{
Margarida Areias Marques Miranda ${ }^{1}$ Pedro Mota ${ }^{2}$ Pedro Cardoso $^{3} \quad$ Alexandre Pereira $^{3}$ \\ Vânia Oliveira ${ }^{3}$ \\ 1 Orthopedics Service, Alto Minho Local Health Unit, Esposende, \\ Address for correspondence Margarida Areias Marques Miranda, \\ Portugal \\ 2 Orthopedics Service, Hospital Center of Trás-os-Montes and Alto \\ Serviço de Ortopedia, Unidade Local de Saúde do Alto Minho, Rua \\ Pedra do Homem, 28, 4740-522, Esposende, Portugal \\ Douro, Vila Real, Portugal \\ 3 Orthopedics Service, Porto Hospital Center, Porto, Portugal \\ (e-mail: margaridaareias89@gmail.com).
}

Rev Iberam Cir Mano 2020;48:61-65.
Abstract
Merkel Cell Carcinoma is a rare type of aggressive and often fatal neuroendocrine tumor of the skin.
Keywords
- carcinoma
- merkel cells
- hand
We report a clinical case of a 56-year-old female with a Merkel cell carcinoma on the left hand, without distant metastasis, treated with surgical excision of the lesion and radiotherapy.
Based on this clinical case a research and review of the literature on this rare neoplasia was carried out.
Resumen
Palabras Clave
- carcinoma
- células de Merkel
- mano
El carcinoma de células de Merkel es un tipo de tumor de piel neuroendocrino raro, agresivo y con frecuencia mortal.
Presentamos un caso clínico de una paciente de 56 años diagnosticada con carcinoma de células de Merkel en el dorso de su mano izquierda, sin metástasis a distancia, tratada con escisión quirúrgica de la lesión y radioterapia.
En base a este caso clínico, se realizó una investigación y revisión de la literatura sobre esta rara neoplasia.

\section{Introduction}

Merkel cell carcinoma (MCC), primary neuroendocrine carcinoma of the skin, ${ }^{1}$ is a rare, potentially fatal tumor, ${ }^{2}$ first described by Toker, in $1972 .{ }^{3,4}$ Currently, it is the most malignant tumor of the skin and has a high rate of recurrence and mortality. ${ }^{5}$ The AEIOU mnemonic was used in English to describe the clinical and demographic characteristics of the tumor: asymptomatic, expanding rapidly, immune suppression, older than 50 years, ultraviolet-exposed/fair skin. ${ }^{6}$ It is a rare tumor, representing less than $1 \%$ of malignant cutaneous tumors. ${ }^{7}$ It occurs mainly on the face and neck (40-60\%), followed by the trunk (33\%) and rarely on the limbs (10$20 \%)^{6,7}$ It is more frequent in the elderly, mainly Caucasian men. In young people, its prevalence is higher in immunocompromised individuals. ${ }^{2}$ Several chromosomal changes associated with MCC have been described, the most frequent being located on chromosomes 1, 6, 11 and 16. Currently, MCC recurrence has been linked to the "Merkel cell polyoma virus" (MCPyV). ${ }^{2}$

Clinically, MCC manifests as a solid, painless, exophytic tumor, skin color or reddish-blue and very aggressive growth, which may increase in weeks to months. ${ }^{2}$ The initial course of MCC is asymptomatic and the lesion may be received

October 9, 2019

accepted

February 28, 2020
DOI https://doi.org/

10.1055/s-0040-1712090. ISSN $1698-8396$.
Copyright $\odot 2020$ Thieme Revinter

Publicações Ltda, Rio de Janeiro, Brazil
License terms

(ㄷ) (i) $\ominus$ (\$) 
clinically and histologically similar to basal cell carcinoma, which often delays the diagnosis. The reason for medical consultation is usually the rapidly progressive growth of the tumor $^{1,5}$ and in the initial consultation approximately $26 \%$ of patients already have lymphatic metastasis and $8 \%$ with distant metastatic disease. ${ }^{8}$ The confirmation of the diagnosis is based on histology and immunohistochemistry, with the expression of epithelial and neuroendocrine markers. ${ }^{9}$ Determining the stage of patients with MCC is of great importance to establish the most appropriate prognosis and treatment. ${ }^{1}$ Tests such as ultrasound, computed tomography $(\mathrm{CT})$, magnetic resonance imaging (MRI) and positron emission tomography (PET)-CT/FDG-PET can be used to complete staging. ${ }^{10}$ The American Joint Committee on Cancer supports the staging system $\mathrm{T}$ (tumor) $\mathrm{N}$ (lymph node) $\mathrm{M}$ (metastases) for MCC. Stage I consists of primary tumors of $2 \mathrm{~cm}$ or less, with no evidence of regional ganglion invasion. Stage II includes primary tumors larger than $2 \mathrm{~cm}$ (T2 or T3) or a primary tumor with invasion of bone, muscle, fascia or cartilage (T4). Stage III is defined as any primary tumor with regional ganglion disease, and stage IV includes tumors with metastases in addition to the regional lymph nodes. ${ }^{5}$

The main treatment for MCC is surgery. Treatment consists of radical surgical resection and radiation therapy. Current surgical margin recommendations are based on the size of the primary tumor. In tumors smaller than $2 \mathrm{~cm}$ the margins of surgical excision should be $1 \mathrm{~cm}$ and $2 \mathrm{~cm}$ for tumors larger than $2 \mathrm{~cm}^{6}$ Sentinel lymph node biopsy is important in the stage and prognosis of MCC. ${ }^{6}$ In stages I and II, without local or distant metastases, radical excision should be performed, accompanied by radiotherapy in patients at risk. In stage III, in which there are locoregional metastases, surgical excision of the lesion should be complemented with excision of the lymph nodes and radiotherapy. In stage IV, or the presence of distant metastases, treatment is palliative involving chemotherapy, complemented by radiotherapy. ${ }^{2}$ The role of chemotherapy in the treatment of MCC remains unclear. Currently, chemotherapy is considered as palliative treatment in cases of disseminated disease and not as adjuvant or primary treatment. ${ }^{6}$ Patients should be periodically monitored due to the high rate of recurrence. ${ }^{10} \mathrm{MCC}$ is particularly aggressive with a relative mortality of approximately $30 \%$ and $50 \%$ at 2 and 5 years after diagnosis, respectively. ${ }^{6}$ Although it is a tumor of fast growth and metastasis, there are published data on spontaneous regression. $^{2}$

We describe a patient with MCC on the back of the wrist. Due to the rarity of the lesion on the upper limb, especially on the dorsum of the wrist, with only two more cases described in the literature, we emphasize the need for early diagnosis and adequate treatment for the good clinical evolution of the patient.

\section{Case Report}

Female patient, 56 years old, was referred to the Orthopedics consultation for massive swelling of the back of the left wrist, with progressive growth over six months. The objective examination showed a swelling of $3 \times 2 \mathrm{~cm}$, solid, adherent

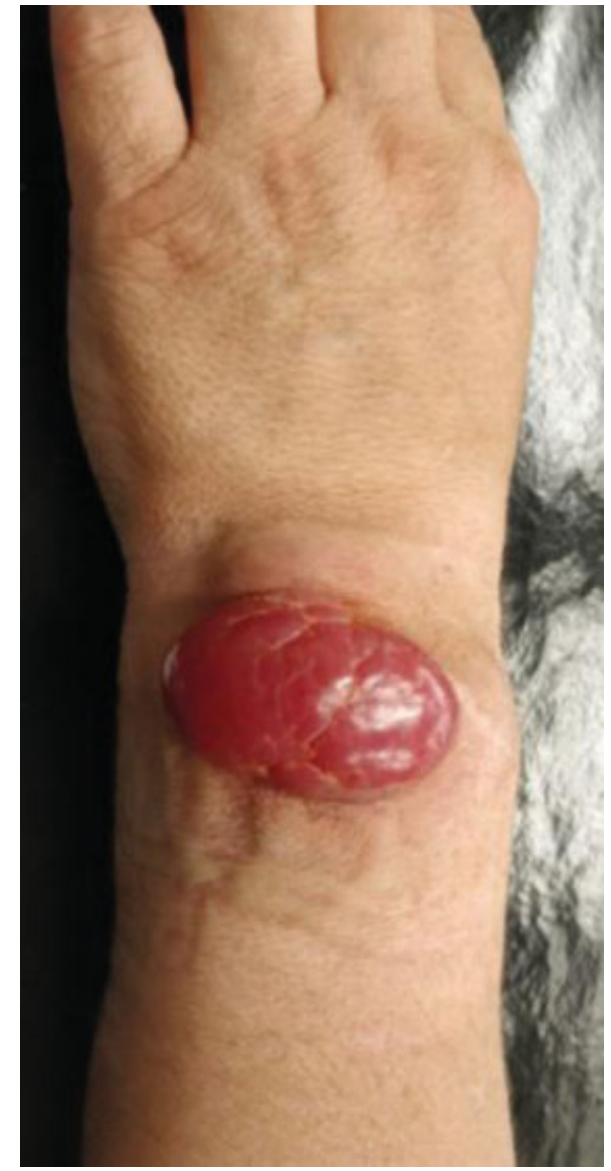

Fig. 1 Bulky swelling of the back of the left wrist.

to the deep planes, reddish in color ( $\mathbf{- F i g . ~ 1 ) . ~ A c t i v e ~ a n d ~}$ passive mobilization of the wrist was painful. Axillary or epitrochlear adenomegalies were not palpable. No neurovascular deficits were detected. NMR of the wrist and hand (-Fig. 2, 3) showed a large tumor, with no apparent involvement of the adjacent major structures, with no apparent bone or tendon invasion. An aspiration biopsy was performed which described a neuroendocrine carcinoma with the possibility of MCC. Chest CT, abdomen and pelvis, and PET-CT, did not show distant lesions. Lymphoscintigraphy marked a sentinel ganglion. Primary surgical treatment was decided. The patient underwent radiographic surgical excision of the sentinel ganglion with a gamma camera and extended excision of the skin lesion (-Fig. 4). The entire extensor tendon compartment of the fingers was resected, and the arthrodesis of the wrist was performed with a plate and screws. Tendon transposition was performed from the radial flexor carpal tendon to the extensor digitorum communis and the abductor pollicis longus (-Fig. 5). The defect is reconstructed using an inverted forearm flap with isolation of the radial pedicle and tunneling to the dorsal area, and coverage of the flap donor area with partial skin graft (-Fig. 6) harvested from the left thigh. The surgery was uneventful. Histological and immunohistochemical examination of the surgical specimen confirmed the diagnosis of MCC and the surgical margins and sentinel ganglion were negative for tumor lesion. The patient underwent 


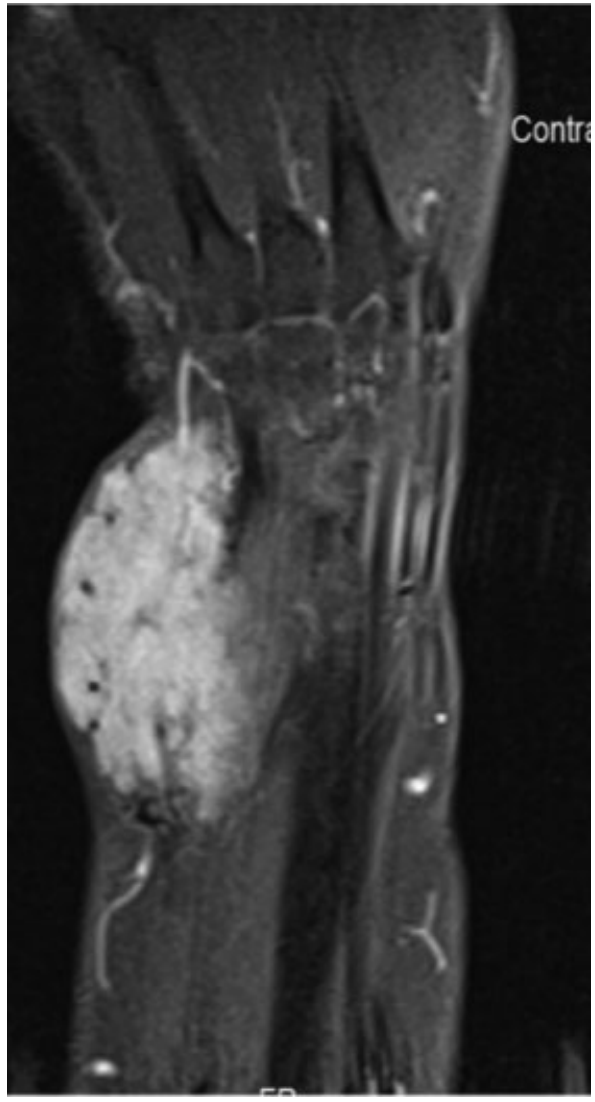

Fig. 2 Coronal CT view of the left wrist.

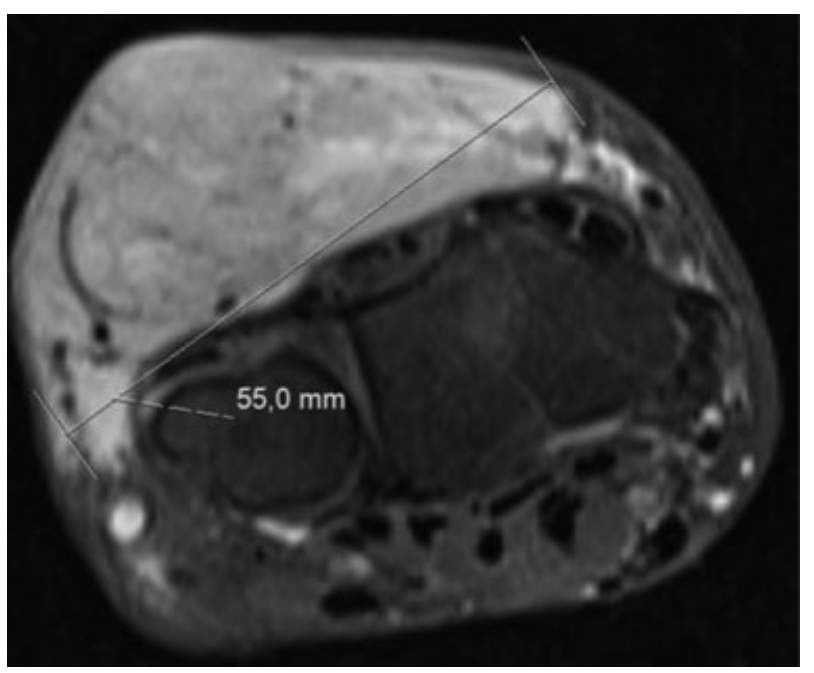

Fig. 3 Axial CT view of the left wrist.

postoperative adjuvant radiotherapy and presented a good clinical and imaging evolution, with no complications or disease recurrence at 12 months after surgery.

\section{Discussion}

The benign aspect of MCC, usually in exposed skin areas, contrasts with its extensive microscopic invasion and may delay diagnosis. ${ }^{2} \mathrm{MCC}$ is a well-known tumor of the skin but

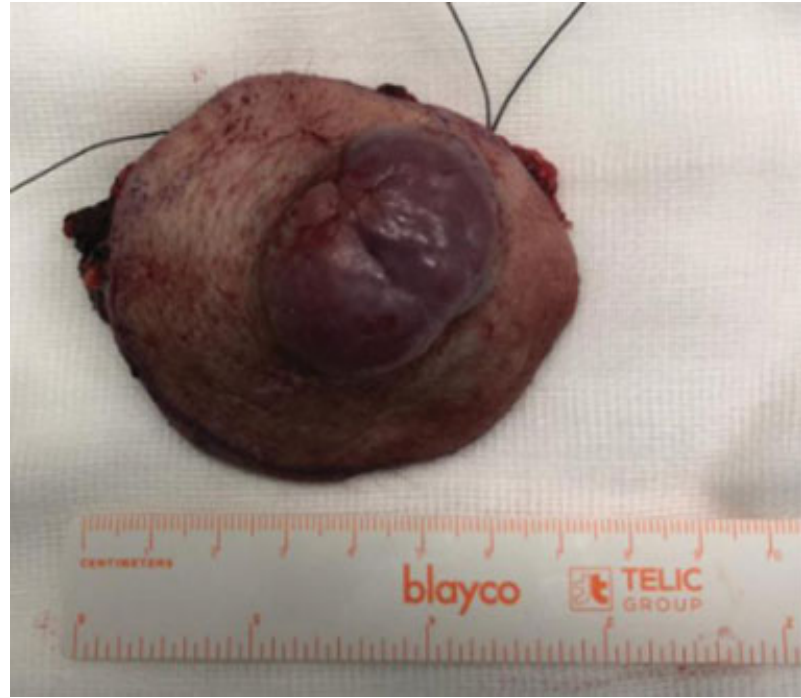

Fig. 4 Surgical resection part.

is rarely described on the upper limb, especially on the wrist and hand. ${ }^{3}$ To date, we are aware of the report of 8 cases of MCC in the upper limb. ${ }^{11}$ The differential diagnosis of MCC should include basal cell carcinoma, squamous cell carcinoma, epidermoid cyst, amelanotic melanoma and skin metastases. ${ }^{2,6}$ In cases of MCC of the fingers, resection of the radius involved has been recommended. ${ }^{11,12}$ For tumors of the dorsum of the wrist and hand, a wide local excision is recommended. ${ }^{13,14}$ However, tumor resections at these sites are associated with greater difficulty in reconstruction, due to the limited viability of soft tissues to cover tendons, adjacent neurovascular structures and carpal bones. ${ }^{11}$ The case presented elucidates the complexity of this type of surgery, requiring a reverse-flow flap to cover the injured area. Factors of poor MCC prognosis, such as male gender, ganglionic or systemic metastasis and primary tumor location in the head, neck or trunk, have been described. However, there are still only reports and small case series that address the prognostic factors or predictors of survival for the upper limb and hand MCC. This lack of evidence-based data can be a problem for reconstructive wrist and hand surgery, just as malignant hand tumors can be a surgical challenge in balancing tumor eradication and limb function conservation. ${ }^{15}$ MCC presents an early locoregional metastasis and recurrence, and both locoregional and distant ganglion metastases are, respectively and independently, associated with worse survival. ${ }^{16}$ Patients with upper limb MCC, compared to other locations, have a slightly longer survival, are diagnosed in earlier stages of the disease and have lower rate of regional and systemic metastasis. However, they still have relatively low overall survival for a skin neoplasm. ${ }^{15}$ In the present clinical case, treatment with surgical excision and radiotherapy seems, to date, to have been an excellent therapeutic option. However, a longer follow-up, at least five years, will be necessary to confirm the success of this approach.

Due to the rarity of these tumors, mainly located in the wrist, a high index of suspicion is necessary, as well as early 


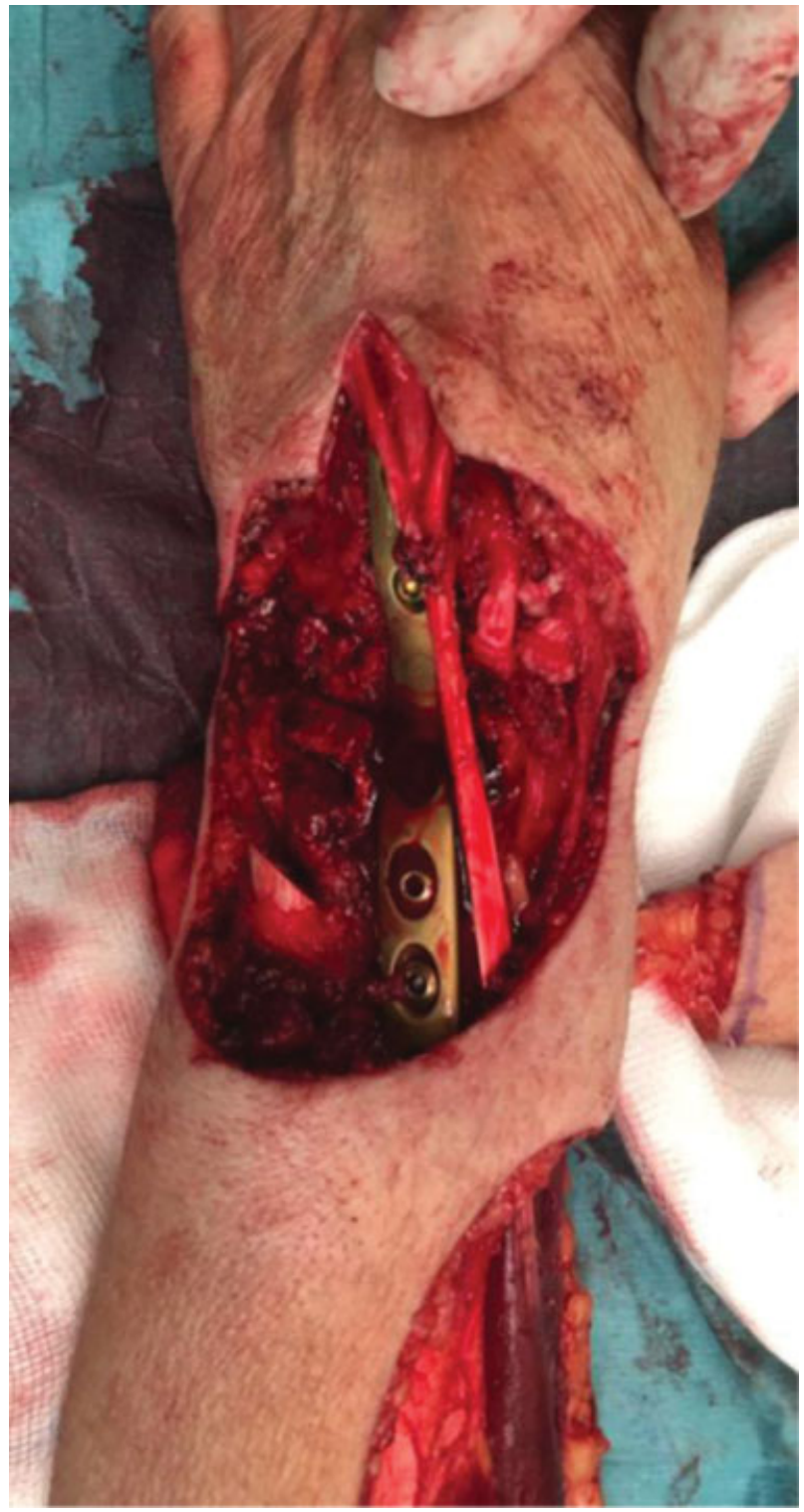

Fig. 5 Intraoperative image-after resection of the tumoral lesion and arthrodesis of the wrist with plate and screws and transposition of the radial flexor of the carpus to the extensor digitorum communis.

diagnosis and adequate treatment, so that the patient evolves in an appropriate way. Thus, the authors consider that the report of this case may alert and make health professionals aware of this serious and lethal pathology.

\section{Conclusion}

MCC is an uncommon and aggressive cutaneous malignant neoplasm ${ }^{6}$ and rarely described in the upper limb. ${ }^{12}$ The primary lesion of the MCC is distinguished by the absence of specific clinical characteristics. ${ }^{6}$ Prevention of MCC and early surgical resection plays a crucial role in the patient's prognosis. ${ }^{2}$ Currently, the guidelines advocate aggressive clinical behavior and highlight the need for coordination of multidisciplinary care in the approach and treatment of this pathology. ${ }^{16}$ Due to the rarity of these tumors and the lack of high quality studies, the MCC of the hand and upper limb

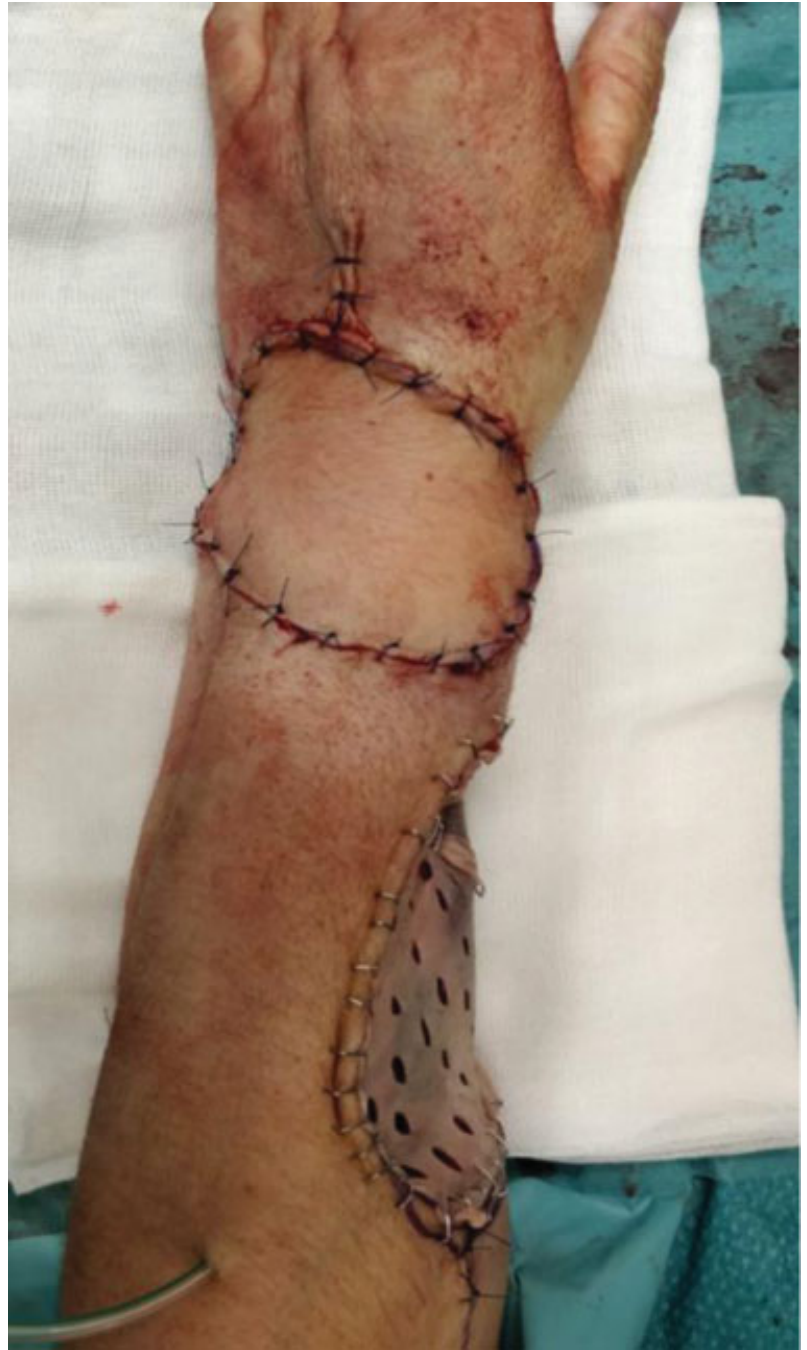

Fig. 6 Postoperative with inverted external forearm on the back of the wrist and skin-free graft in the donor area.

has not been adequately described ${ }^{17}$ and a high index of suspicion is needed. ${ }^{9}$ Thus, the authors consider that the report of this case may alert and raise awareness among health professionals, especially in the pathology of the skin and hand, in the recognition of this neoplasia and assist in the early approach and treatment.

\section{Conflict of Interests}

The authors declare that have no conflict of interests.

\section{References}

1 Llombart B, Requena C, Cruz J. Actualización en el carcinoma de células de Merkel: Epidemiología, etiopatogenia, clínica, diagnóstico y estadificación. Actas Dermosifiliogr 2017;108(02):108-119

2 Pink R, Ehrmann J, Molitor M, et al. Merkel cell carcinoma. A review. Biomed Pap Med Fac Univ Palacky Olomouc Czech Repub 2012;156(03):213-217

3 Daghistani W, Younan R, Brutus JP. Merkel cell carcinoma of the hand: case report and literature review. Chir Main 2010;29(02): 128-131

4 Toker C. Trabecular carcinoma of the skin. Arch Dermatol 1972; 105(01):107-110 
5 Parcells AL, Lee ES, Fleegler EJ. Merkel cell carcinoma of the hand. J Hand Surg Am 2014;39(07):1421-1423, quiz 1424

6 Wang TS, Byrne PJ, Jacobs LK, Taube JM. Merkel cell carcinoma: update and review. Semin Cutan Med Surg 2011;30(01):48-56

7 Agelli M, Clegg LX. Epidemiology of primary Merkel cell carcinoma in the United States. J Am Acad Dermatol 2003;49(05): 832-841

8 Harms PW. Update on Merkel Cell Carcinoma. Clin Lab Med 2017; 37(03):485-501

9 David S, Riah Y, Lebreton E. Merkel cell carcinoma of the hand. J Hand Surg Eur Vol 2011;36(05):426-427

10 Amaral T, Leiter U, Garbe C. Merkel cell carcinoma: Epidemiology, pathogenesis, diagnosis and therapy. Rev Endocr Metab Disord 2017;18(04):517-532

11 Min HJ, Kim JH, Kim YW, Cheon YW. Merkel Cell Carcinoma of the Wrist: A Case Report. Ann Plast Surg 2018;81(02):244-247
12 Mikolyzk DK, Bednar MS. Merkel cell tumor of the hand: report of two cases. J Hand Surg Am 2008;33(03):404-406

13 Tai P. Merkel cell cancer: update on biology and treatment. Curr Opin Oncol 2008;20(02):196-200

14 Dancey AL, Rayatt SS, Soon C, Ilchshyn A, Brown I, Srivastava S. Merkel cell carcinoma: a report of 34 cases and literature review. J Plast Reconstr Aesthet Surg 2006;59(12):1294-1299

15 Soltani AM, Allan BJ, Best MJ, Panthaki ZJ, Thaller SR. Merkel cell carcinoma of the hand and upper extremity: current trends and outcomes. J Plast Reconstr Aesthet Surg 2014;67(03):e71-e77

16 Miles BA, Goldenberg D; Education Committee of the American Head and Neck Society (AHNS). Merkel cell carcinoma: Do you know your guidelines? Head Neck 2016;38(05):647-652

17 Westerveld D, Hall D, Richards W. Merkel Cell Carcinoma of the Hand: A Case Report and Review of the Literature. American Association for Hand Surgery 2016;11(04):24-29 